ISSN:1991-8178
EISSN: $2309-8414$
DOI: $10.22587 /$ ajbas.2017.11.16.5
Journal home page: www.ajbasweb.com

\title{
Histological and Histochemical Characteristics of the Kidneys in Different Avian Species
}

\author{
${ }^{1}$ Ali F. Reshag, ${ }^{2}$ Dhyaa Ab. Abood and 2 Ektifaa, S. Khayoon \\ ${ }^{1,2,2}$ Department of Anatomy, Histology and Embryology, College of Veterinary Medicine University of Baghdad, Iraq.
}

\section{Address For Correspondence:}

Ali F.Reshag, Department of Anatomy, Histology and Embryology, College of Veterinary Medicine University of Baghdad, Iraq E-mail: Sabahali503@yahoo.com

\section{A R T I C L E IN F O}

\section{Article history:}

Received 12 October 2017

Accepted 22 December 2017

Available online 31 December 2017

Keywords:

Histological, histochemical, kidney, ureter, birds, avian.

\begin{abstract}
A B S T R A C T
Background: Birds vary according to the food they eat that depending on the environment they are live in, including marine birds, wild birds, carnivores birds and domesticated birds, each of which has a diet that makes the kidneys in different types of species perform different, privet and unique functions than those that are different in the environment. Objective: The present work was carried out to investigate the histological and histochemical characteristics of kidneys in six avian species including domesticated bird (Chicken \& Pigeon), wild bird \& Amphibious bird (Common coot \& Purple swamp), and migrated marine birds (Mallard duck \& great Flamingoes). Results: The kidney tissue sections were fixed in $10 \%$ neutral buffer formalin, prepared by paraffin technique and stained with $\mathrm{H} \& \mathrm{E}$, Alcian blue $(\mathrm{pH}$ 2.5), Periodic acid-Schiff and the mercury bromophenol blue stain. Histologically, there were no differences found in the structure of the kidney among these species. Histochemically the endothelial cells of glomerular capillary tuft were resting on delicate basement membranes which were positive for PAS stain and negative for Alcian blue $(2.5 \mathrm{pH})$. The basement membrane of lining cells of all segments of nephrons and brush border of proximal convoluted tubules were positive for PAS stain and negative for Alcian blue (2.5pH). The luminal surfaces of the distal convoluted tubules and collecting ducts were positive For Alcian blue (2.5pH). With combined Alcian blue - PAS stains the distal convoluted tubules and collecting ducts were strongly positive to Alcian blue $(2.5 \mathrm{pH})$. The proximal convoluted tubules were the first site where the albumin in composed of spheres formed. Conclusions: The avian nephrons were similar in various birds species showed variable $\mathrm{pH}$ reactions substances to produce small renal spheres in proximal tubules, consequently the harmful effect of the uric acid crystals prevented by a chemical binding of uric acid with matrix protein.
\end{abstract}

\section{INTRODUCTION}

The avian kidneys have differed from those of other mammal species, the avian kidney consists of three separated lobes (Nabipour, et al., 2009) (Mobini and Abdollahi, 2016). Avian kidney characterized by relatively long medulla that surrounded by the cortex and forming many of renal cones (Abood et al., 2014). On the other hand avian kidney has no renal pelvic, thus it drains its secretion throughout pair of ureter branches (Sreeranjini et al., 2010). Also the structure of the avian kidney has two types of nephrons ; reptilian and mammalian types (Reshag et al., 2016) (Abood et al., 2014) (Mobini and Abdollahi 2016). All these histological differences make the function of the birds urinary system is more complex. Many studies have involved the histochemisty of the avian urinary system (Nabipour, 2008) in bat, (Oliaii \&Mobini 2017) in Japanese Quail, (Sivakumar, et al., 2012), in Guinea Fowl, (Batah, 2012) in coot bird. The comparative detailed study of the pH reactions in different regions of the kidney nephrons not yet found. The difference in the $\mathrm{pH}$ reactions at the different kidney

Open Access Journal

\section{Published BY AENSI Publication}

(C) 2017 AENSI Publisher All rights reserved

This work is licensed under the Creative Commons Attribution International License (CC BY).

http://creativecommons.org/licenses/by/4.0/

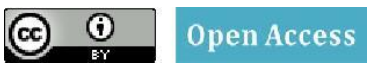

To Cite This Article: Ali F.Reshag, Dhyaa Ab. Abood and Ektiffa S.K., Histological and Histochemical Characteristics of The Kidneys In Different Avian Species . Aust. J. Basic \& Appl. Sci., 11(16): 36-44, 2017 
nephrone play an important role in expelled more nitrogenous waste product (Gasotti and Braun, 2004). Due to the specific $\mathrm{pH}$ of the proximal tubular fluid, the anionic albumins \& uric acid have attracted those of cationic sodium and potassium salts to form the urate spheres (Braun and Pacelli, 1991).

\section{MATERIALS AND METHODS}

Eighteen adults of different six species, birds involved (Chicken, Pigeon, Common coot, Purple swamp, Mallard duck \& great Flamingoes) (Three birds each) have chosen for this work. All birds have purchased from Baghdad local markets. This work was accomplished in the laboratory of histological techniques in the department of Anatomy, Histology \& Embryology at College of Veterinary Medicine, University of Baghdad. According to Animal Care and Use Procedure (ACUP), birds have euthanized by intravenous injection of an overdose of sodium pentobarbital, (Dose; 100-150 mg/kg) through the wing vein (Pavek, 2007), then the birds sacrificed. Small pieces of kidneys were fixed in neutral buffer formalin $10 \%$, routinely processed and embedded in paraffin and tissue sections were cut at $5 \mu \mathrm{m}$ thickness. For general histological features, the tissue sections have stained with Hematoxylin and Eosin-phloxine stain. For detection the glycogen and neutral mucopolysaccharid the sections have stained with Alcian blue (AB)(2.5pH) and Periodic Acid-Schiff (PAS) stains to distinction between acidic and neutral mucopolysaccharid the combine AB \& PAS was done (Bancroft and Marilyn, 2002).The locations of protein coated spheres in nephron parts were detected using the mercury bromophenol blue method (AL-Taai, Dhyaa 2015).

\section{Preparation of individual nephron:}

To determine the types of the individual nephron and examine their gross morphology the kidney specimens have been kept overnight at $4 \mathrm{C}$ in alcoholic ferric chloride solution which contained $95 \mathrm{ml}$ ethyl alcohol, $5 \mathrm{ml}$ concentrated $\mathrm{HCl}$, and $30 \mathrm{~g}$ ferric chloride. Then the specimens have digested by $20 \% \mathrm{HCl}$ solution at $37 \mathrm{C}$ for $(2 \mathrm{~h})$. Then the tissue cooling at (4C) in acid ferric chloride solution (200 mg ferric chloride, $0.2 \mathrm{ml}$ acetic acid, $100 \mathrm{ml}$ distilled water). Then the kidney specimens place in water for 4-12 $\mathrm{h}$ to soften. Finally the individual nephrons were dissected free using glass needles and were transferred to a drop of $50 \%$ glycerol on a microscope slide (Braun and Dantzler, 1972).

\section{Results:}

\section{The histological results:}

In all breed studied, the kidneys were have divided into three lobes, each lobe showed polygonal lobules which enclosed central vein. Each lobule was subdivided into wide cortex and small medulla cone (Fig.1).Within cortex there were two types of renal corpuscles (Fig.2), the first was the mammalian type which had large renal glomeruli showed well developed loop of Henle with thin and thick segments, the second type was the reptilian type which had small renal glomeruli and characterized by lacked the loop of Henle (Fig.3). Renal corpuscle has composed of glomerulus which surrounded by Bowman's capsule and consisted of the central core of mesangial cells those surrounded by podocytes (Fig.4).within cortex, the other cortical components were proximal, distal convoluted tubules, collecting tubule and perilobular collecting ducts along with the many peritubular capillary sinuses, the proximal convoluted tubules were lined with a simple cuboidal epithelium showed brush border and narrow lumen, while the distal convoluted tubules were lined by a simple cuboidal epithelium showed wide lumen and smooth apical surface (Fig.4). Within the medullary cone, the collecting duct was intermingled between the thick and thin limbs of loop of Henle, the collecting tubules were lined by columnar epithelium, and thick limbs of the loop of Henle were lined by low cuboidal epithelium while the thin limbs of loop of Henle were lined by flat epithelial cells (Fig. 5).

\section{The histochemical results:}

The parietal layer of Bowman's capsule of renal corpuscles and the delicate basement membranes of endothelial cells of capillary tuft were positive for PAS satin and negative for Alcian blue (2.5pH) stain (Fig.4).The cytoplasm of lining epithelial cells of the proximal convoluted tubules, luminal brush border and its basement membrane have contained of positive reaction substances to PAS stain, that indicated the presence of neutral glycoprotein and these substances were negative to Alcian blue $(2.5 \mathrm{pH})$ stain (Fig.4).The cytoplasm of lining epithelial cells of the distal convoluted tubules and collecting tubules were negative for PAS reaction, while their luminal surfaces had mucous secretion that showed positive reaction for Alcian blue $(2.5 \mathrm{pH})$ stain (Fig.4\&6).The basement membrane and the luminal surfaces of thick and thin limbs of loop of Henle were positive PAS stain and negative for Alcian blue $(2.5 \mathrm{pH})$ stain (Fig.5).The epithelial lining and glands of lamina propria of branches of ureter also were positive for Alcian blue stain (Fig.7). The mercury bromophenol blue stain revealed that the albumin coated spheres were observed in the proximal renal tubules which give deep blue color which indicate the presents of albumin in composition of spheres (Fig.8). 


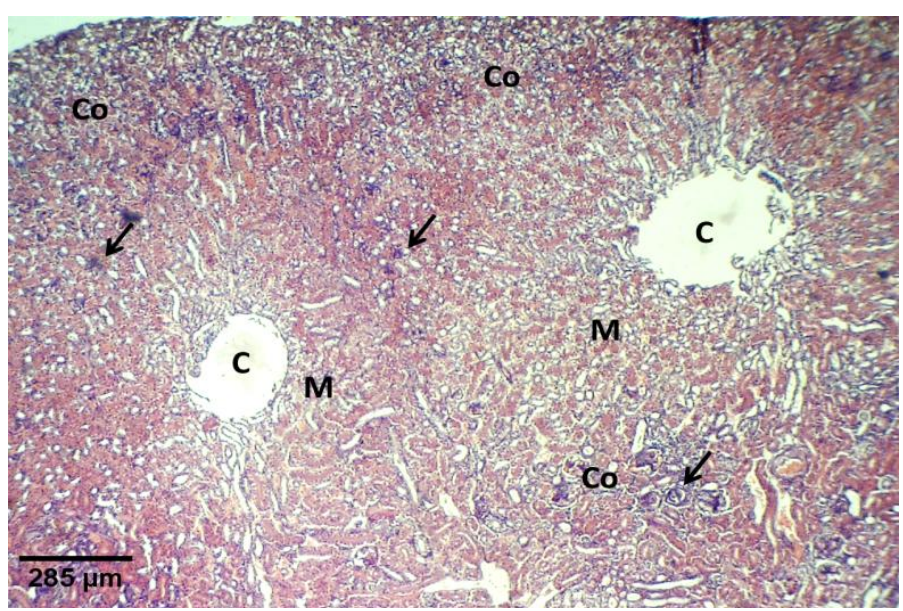

Fig. 1: The pigeon kidney lobules show: cortex (Co), medulla (M), central vein (C) and renal corpuscles (arrows). (H\&E) stain.

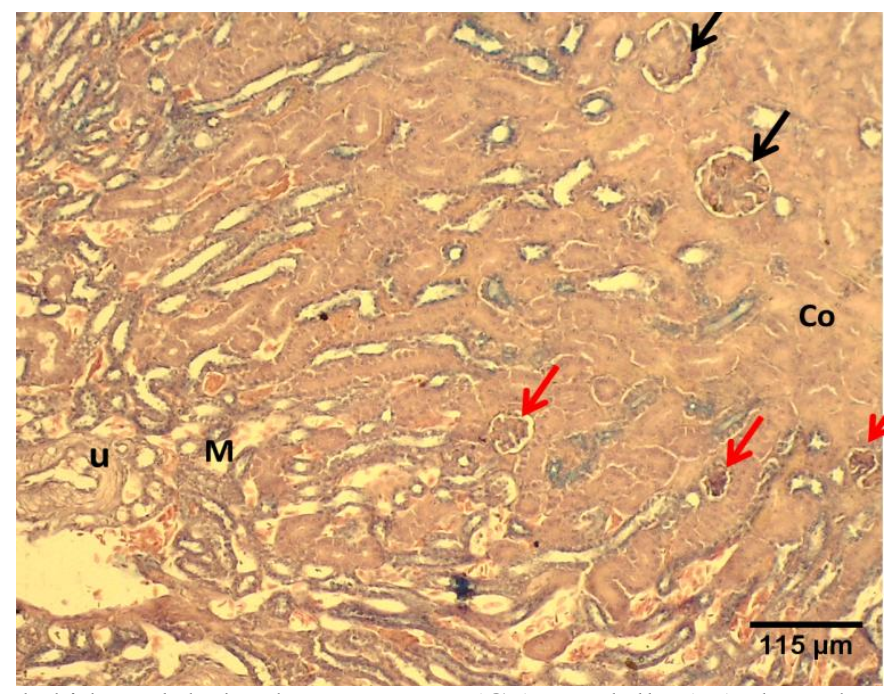

Fig. 2: The Mallard duck kidney lobule shows: cortex (Co), medulla (M), branch of ureter (u), mammalian nephrons (Black arrows) and reptilian nephrons (Red arrows). H\&E- phloxine stain

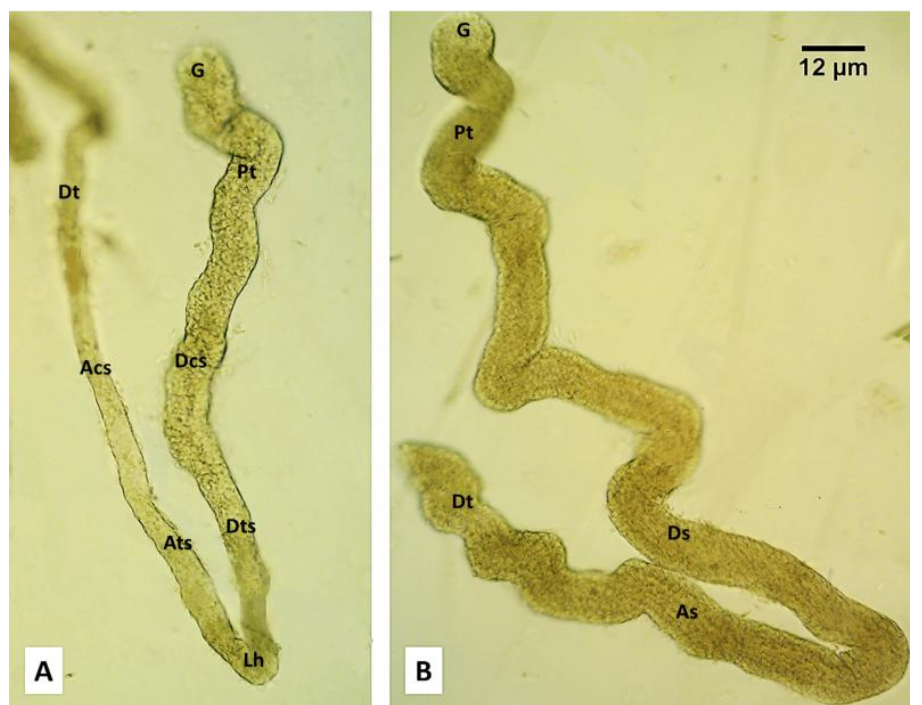

Fig. 3: The isolated renal nephrons. Micrograph (A) shows mammalian nephron and micrograph (B) shows: reptilian nephron: glomerulus $(\mathrm{G})$, proximal convoluted tubules $(\mathrm{Pt})$, descending thick segment (Dcs), descending thin segment (Dts), loop of henle (Lh), Ascending thin segment (Ats) Ascending thick segment (Acs)\& distal convoluted tubules (Dt). 


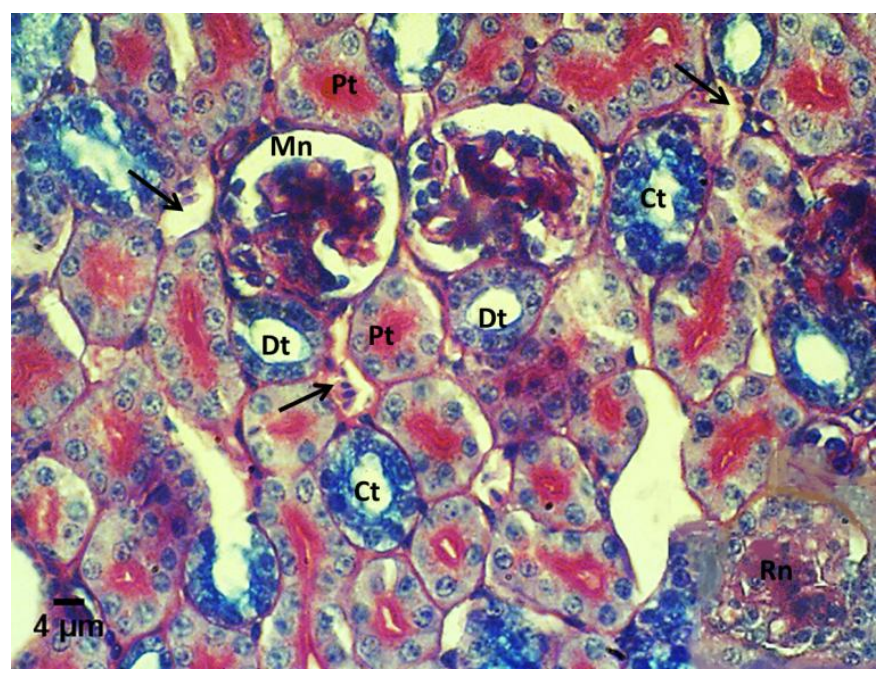

Fig. 4: Section of kidney (Common coot) shows: Mammalian nephron (Mn), reptilian nephron (Rn), proximal convoluted tubules $(\mathrm{Pt})$, distal convoluted tubules $(\mathrm{Dt})$, collecting tubules $(\mathrm{Ct}) \&$ peritubular capillary (arrows). Combined Alcian blue $(2.5 \mathrm{pH})$ \&PAS stains.

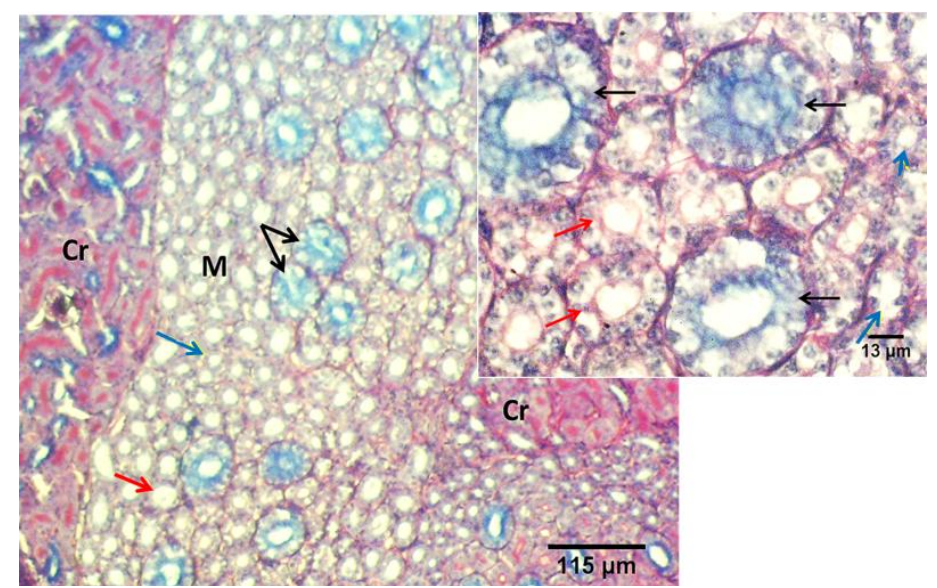

Fig. 5: The section of the kidney (Common coot)shows: Cortex (Cr), medulla (M), collecting duct (Black arrows), thick segment of loop of Henle (Red arrows) and thin segment of loop of Henle (Blue arrows). Combined Alcian blue \&PAS stains.

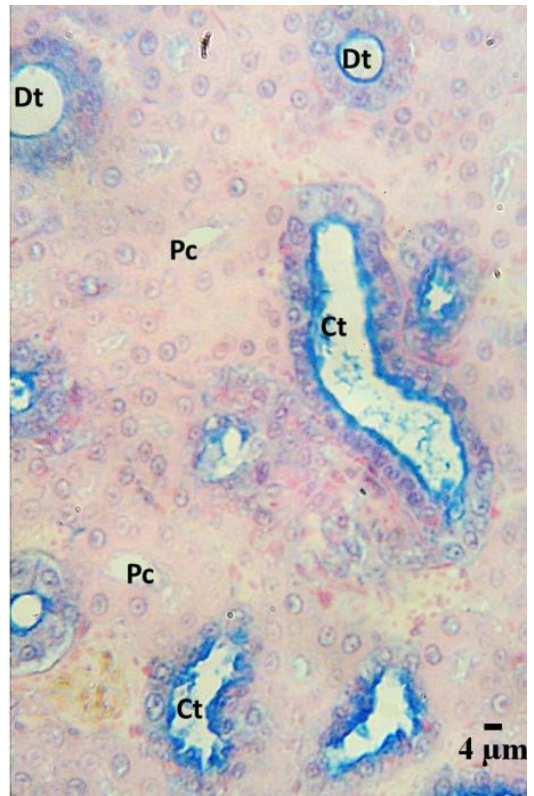

Fig. 6: Section of kidney of the chicken shows: proximal convoluted tubules $(\mathrm{Pt})$, distal convoluted tubules (Dt) and collecting tubules $(\mathrm{Ct})$. Alcian blue $(2.5 \mathrm{pH})$ stain. 


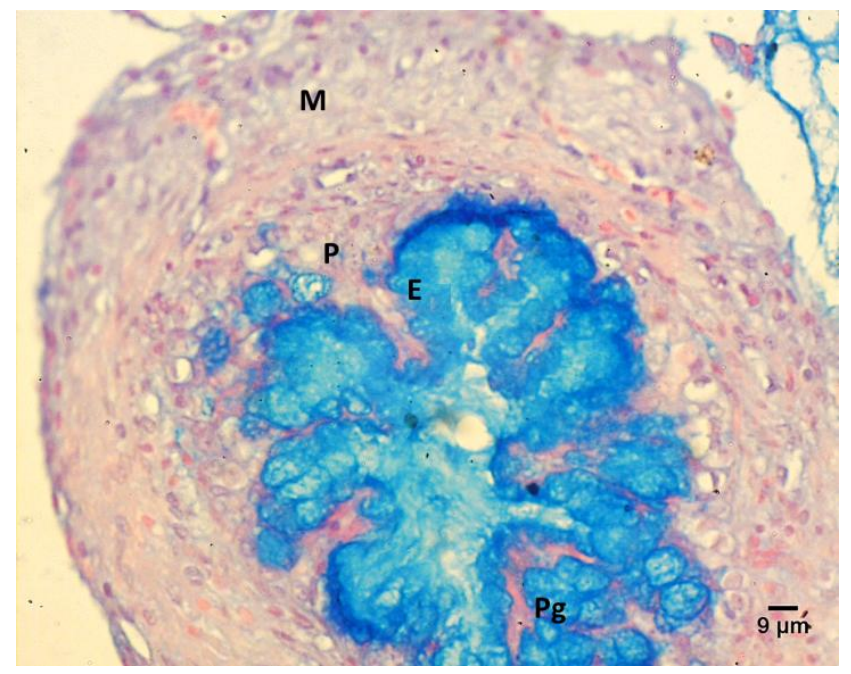

Fig. 7: The branch of ureter (chicken) shows: epithelium contained mucous secretion (E), lamina propria (P) with sub epithelial glands contained positive Alcian blue stain secretion (pg). Combine Alcian (2.5pH) \&PAs stains.

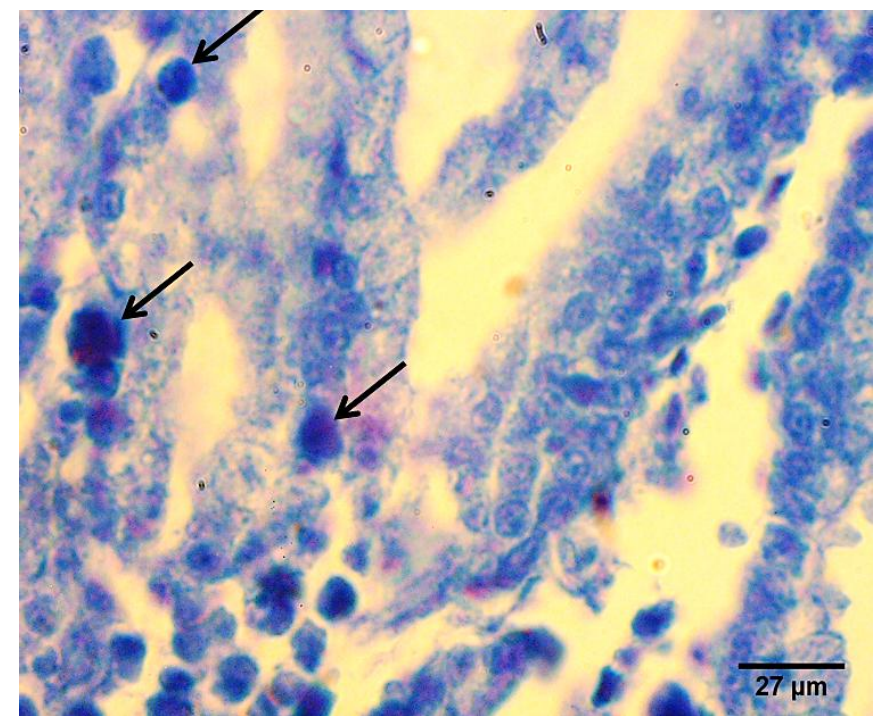

Fig. 8: The proximal convoluted tubules (chicken) shows: spheres with dark blue stain (arrows). Bromophenol blue stain.

\section{Discussion:}

The present study conducted both the histological and histochemical characteristics of avian kidney and role of the mucopolysaccharid and albumin in protection of urinary system from the effects of urate crystals, in general, all avian species involved in this work, the kidney were lobular organ with wide cortex and small medulla, such a result is consistent with results of (Richardson et al.,1991) who studied the kidney of bird from North America, (Sivakumar et al., 2012) in Guinea fowl, (Abdulla et al., 2014) in passer domesticus, (Abood et al., 2014) in harrier, chicken and mallard duck, (Michalek et al., 2016) in breeding emu and (Casotti and Richardson, 1992) who found higher cortical volume in the kidneys of wet zone Honeyeater and in arid zone honeyeaters a higher medullary volume which related with environmental and dietary habits. this result suggest that the high cortical volume in compare to low medulla volume are associated with kidney ability for more urine concentration and water conservation and vice versa (Abood, et al.,2014).Our result revealed two types of the renal corpuscles; mammalian type and reptilian type, such observations have recorded by Tsulcamoto et al. (2005) in chicken, (Nishimura, 2008) in marine birds,(Michalek et al., 2016) in breeding emu, (Batah, 2012) in coot bird, (Abdulla et al., 2014) in passer domesticus. The most type of the avian nephron was the repitaliane type and there was not more of $30 \%$ of the nephron was the mammalian type (Carpenter, 2003; Casotti and Braun, 2000). In the present result the intermediate type of corpuscle was not observed, this result was as well that of the previous study by (Sivakumar et al., 2012) the intermediate type of corpuscle has recorded by (Mobini and Abdollahi, 2016) in Japanese quail and by (Abood et al., 2014) in Chick \&harrier, the reptilian 
type of renal corpuscles might limit the capacity of the kidney produce hyperosmotic urine and the mammalian corpuscles are essential for concentrated urine (Nishimura and Fan, 2003), this result suggest that, much of the mammalian and intermediate types of corpuscles in breeds are related with birds food habits, so these nephrons play an important role conserving body water. The structure of renal corpuscle was similar to those results mentioned by (Nabipour, 2009, Abood et al., 2014).Other cortical region components were proximal convoluted tubules, distal convoluted tubules, collecting tubules and per lobular collecting ducts along with the many peritubular capillary sinuses, this results concurs (Al-Ajeely and Mohammed, 2012; Sivakumar et al., 2012; Abood et al., 2014; Michalek et al., 2016), (Nabipouret al., 2009).In our results the pariet al layer of Bowman's capsule and the endothelial cells of the capillary tuft basement membranes were delicate structure that reacted positive with PAS stain as described by Sivakumar et al., (2012) in birds and El -Daly(2013) in mammals, this suggested that, the neutral $\mathrm{pH}$ of delicate basement membranes of capillaries lead to extruding a fluid from plasma with its electrolyte and water composition as the glomerular filtrate (Cunningham \& Klein, 2007). The present result revealed the cytoplasm of epithelial cells and the lumen of proximal convoluted tubules contained positive PAS substances, that indicated the presence of neutral glycoprotein in this part of nephron, this result accord with result revealed that, in of rock dove the lumen of the proximal convoluted tubules contained PAS positive substances (Nabipour 2009; Sivakumar et al., 2012; Sreeranjini et al., 2000; Mobini \& Abdollahi, 2016), also this result is compatible with result of (Brandon et al., 2009) in Juvenile American Alligator.On the other hand results of El-Daly,(2013) concluded that, the carbohydrates and proteins have increased after nephrone compartments (glomeruli, basement membrane of the tubules and brush border of proximal tubules) have exposed for green tea in compared to that group which exposed to harmful exogenous substances, this elevation could be due to an increase in the re-absorption of kidney tubules or might be due to an increase in glycogen synthesis or a decrease in glycogen breakdown by phosphorylase, which causes a glycogen recovery in the tissue. Meanwhile (Elasrag, 2010; El-Daly, 2011) reported that the main causes related with presence of PAS substances was due to influence of disturbances in the metabolism of organic compounds such as carbohydrates and proteins. The present result suggest that the presence of PAS substances in upper part of renal nephron is related with a way of elimination mechanisms against harmful excretion like urate in avian kidney such suggestion has supported by report of Wright et al., (2014) who stated that in vertebrates the increased of renal ammonia eliminated is associated with metabolic acidosis and glycoproteins in the kidney of the freshwater carp play an essential role in regulating ammonia excretion during chronic metabolic acidosis. Our result showed the lining epithelia of distal convoluted tubules and collecting ducts were positive for Alcian blue $(2.5 \mathrm{pH})$ stain, this result disagree with (Sreeranjini et al., 2000) \&(Nabipour, 2008) who stated that the collecting ducts did not give positive reaction in Alcian blue-PAS staining in insectivorous Bats. The result revealed that the distal part of nephron (Basement membrane, lining epithelia, and the luminal surfaces of thick \& thin limbs of loop of Henle) were PAS positive, this findings conceded with results of (Nabipour, 2008; El- Salkh, et al., 2008). The epithelium and sub epithelial glands of branches of ureter were positive to Alcian blue $(2.5 \mathrm{pH})$ stain such results was coincided with observation of (Oliaii and Mobini, 2017) and with opinion says that the acidic mucin in this part of avian urinary system, provides an acidic environment to kept the structure of sphers until excreted outside of urinary system that associated with an increase in uric acid excretion in feeding a high protein diet (Lowell Parsons, 2007), our result suggested that the acidic medium prevent growth of harmful microorganisms. The proximal tubules showed luminal urate spheres, the current result is agreed with result of Casotti and Braun (2004) who reported that the urate spheres is formed in proximal convoluted tubules in packaging containing uric acid, albumin and ions without forming large crystal which could lead obstruct or injury the renal tubules, aslo Bataille, et al., (2008) mentioned that, the active transport system of the brush-border of the proximal tubules epithelium is responsible for discared the majority of urates. on the other hand this result disagree with result reported that the smaller aluminous uric acid sphers is formed initially through the glomerular filtration barrier (Boykin, 1995).

\section{Conclusion:}

In the present study the results have been concluded that, in all avian species studied the histological structure of the kidney is similar and the kidney lobule was the functional unit of the avian kidney which almost has the higher cortical volume with two main types of renal corpuscles; mammalian and reptilian types and small medullary volume. When number of one of the renal corpuscles is exceeded the other type the function of the urine concentration and water conservation could influenced. The urine concentration and water conservation usually related to environment and dietary habits of birds. The histochemical composition of the kidney functional units in different avian species also similar, which revealed variable $\mathrm{pH}$ substances within the regions of the nephrone that primarily responsible for production of packages containing uric acid in the form of small renal spheres in proximal convoluted tubules, the active transport system of the brush-border of the proximal tubule epithelium is responsible for discard the majority of the urates. The harmful effect of the uric acid crystals prevented by a chemical binding of uric acid with matrix protein. The presence of positive PAS mucopolysaccharid in the Bowman's capsule, the basement membrane and apical surfaces of the lining 
epithelium lead to extruding a fluid from plasma with its electrolyte and water composition. The intra cytoplasm content of neutral glycoprotein in epithelial cells and the lumen of proximal convoluted tubules associated within increase in glycogen synthesis or decrease in glycogen breakdown. The presence of PAS substances in upper part of renal nephrone is related with a way of eliminating mechanisms against harmful excretion like urate in avian kidney. The distal parts of nephrone have been shown a positive reaction with Alcian blue $(2.5 \mathrm{pH})$ stain, this means the distal part of the nephrone and the epithelium and sub epithelial glands of the ureter contained acidic mucin that provides an acidic environment to keep the structure of sphers until excreted outside of urinary system and with an increase in uric acid excretion in feeding a high protein diet in addition the acidic medium prevent growth of harmful microorganisms. In our perspectives, it is important in future research attempting to study the microstructure of spheres in various bird of birds with different food habits. It is important to investigate in attempts discharged the renal stones by a dynamic therapy mode similar that in proximal convoluted tubules by coating renal crystals in human similar that in birds.

\section{ACKNOWLEDGMENT}

The authors would like to acknowledge the technical staffs in Department of Anatomy, Histology and Embryology at College of Veterinary medicine, University of Baghdad for providing facilities for carrying out this study. 


\section{REFERENCES}

Al-Ajeely, R.A.G.A. and F.S. Mohammed, 2012. Morpho-histological study on the development of kidney and ureter in hatching and adulthood racing pigeon (Columba livia domestica). International Journal of Science \& Nature, 3: 665-673.

Abdulla, D.A.R., H.A.M. Dauod and H.A. AL-Dalimy, 2014. Morphological Description and Histological Structure of kidney in passer domesticus. Diyala journal for pure sciences, 10: 9-23.

Abood, D.A., A.F. Reshag, S.K. Azhar and A.A. Myson, 2014. Comparative anatomical and histological features of the kidney in harrier (Circus aueroginosus), chicken (Gallus domesticus) and mallard duck (Anas platyrhynchos). The Iraqi Journal of Veterinary Medicine, 38(1): 107-113.

ALtaii, D.A., 2015. Histomorphological and Histochemical study on pre and post hatching development of the female genital system in Mallard Duck (Anas platyrhynchos). (PhD) thesis,College of Veterinary Medicine - University of Baghdad.

Bataille, A.M., J. Goldmeyer and J.L. Renfro, 2008. Avian renal proximal tubule epithelium urate secretion is mediated by Mrp4. American Journal of Physiol., 295: R2024-R2033.

Bancroft, J.D. and G. Marilyn, 2002. Theory and practice of histological techniqes. London, Elsevier Limited.

Bingaman, S., N. Choudhury and V.H. Huxley, 2001. Species-specific properties of serum albumin. FASEB J 15: A45.

Batah, A.L., 2012. Morphological and histological study for the kidneys of coot bird (Fulica atra). Basra Journal of Veterinary Research,11: 128-136.

Boykin, S.L.B., 1995. Relationship between protein and urate in avian urine [Ph.D.]: University of Arizona.

Brandon, C.M., H. Kelly, C. Ashley, L. Ashley, M. Ketan and J.G. Louis, 2009. Morphology and Histochemistry of Juvenile American Alligator (Alligator mississippiensis) Nephrons. Anatomical Record, 292: 1670-1676.

Braun, E.J. and W.H. Dantzler, 1972. Function of mammalian- type and reptilian- type nephrons in kidney of desert quail, American .Journal Of Physiologi, 222(3): 617-629.

Braun, E.J., 2003. Regulation of renal and lower gastrointestinal function: role in fluid and electrolyte balance. Comparative Biochemistry \& Physiology, 136: 499-505.

Braun, E.J. and M.M. Pacelli, 1991. The packaging of uric acid in avian urine. Federation of American Societies for Experimental Biology Journal,5: A1408.

Carpenter, S., 2003. Avian urinary system. Journalof Experemental Biology, 311: 171-182.

Cunningham, J.G. and B.G. Klein, 2007. Textbook of veterinary physiology. Luis Saunders.

El- Salkh, B.A., Z.T. Zaki, M.I. Basuony and H.A. Khid, 2008. Anatomical, Histological and Histochemical Studies on Some Organs Of True Desert Rodents In The Egyptian Habitats. The Egyptian Journal of Hospital Medicine, 33: 578-306.

Elasrag, M.A., 2010. Protective effect of some medical plants against probable genotoxic effects of certain antibiotic on certain mammal. (MSc) Thesis- University of Benha, Egypt.

El-Daly, A.A., 2013. Histological and histochemical effects of green tea extract on enrofluxciacine induce kidney injury in Albino rats. Egypt. Journal of Experemintal Biology and Zoololgy, 9(2): 237-245.

El-Daly, A.A., 2011. The protective effect of green tea extract against Enrofluxacine action on the rat liver; histological, histochemical and ultrastructural studies. Journal of American Science, 7(4): 669-679.

Gasotti, G. and E.J. Braun, 2004. Protein Location and Elemental Composition of Urine Spheres in Different Avian Species. Journal of Experemintal Zoology, 301: 579-587.

Casotti, G. and E.J. Braun, 2000. Casotti G, Braun EJ (2000). Renal anatomy in sparrows from different environments. Journal of Morphology, 243: 283-291.

Casotti, G. and K.C. Richardson, 1992. A stereological analysis of kidney structure of honeyeater birds (Meliphagidae) inhabiting either arid or wet environments. Journal of Anatomy, 180: 281-288.

Lowell Parsons, C., 2007. The Role of the Urinary Epithelium in the Pathogenesis of Interstitial Cystitis/Prostatitis/Urethritis. Urology, 69: 9-16.

Michalek, K., D. Szczerbinska, M. Grabowska, D. Majewska and M. Laszczynska, 2016. Anatomical and morphological study of the kidneys of the breeding emu. (Dromaius novaehollandiae). Turky Journal of Zoology, 40: 314-319.

Mobini, B. and M. Abdollahi, 2016. Effect of sex on histological and histochemical structures of different parts of the kidney in Japanese quail. Poultry Scecncei, 95(9): 2145-50.

Nabipour, A., 2008. Histological Structure of the Kidney of Insectivorous Bats. World Journal of Zoology, 3(2): 59-62.

Nabipour, A., E. Alishahi and M. Asadian, 2009. Some Histological and Physiological Features of Avian Kidney. Journal of .Applied Animl Research, 36: 195-198. 
Nishimura, H., 2008. Urine concentration and avian aquaporin water channels. Pflugers archive European Journal of Physiology, 456: 755-768.

Nishimura, H., and Z. Fan, 2003. regulation of water movement across vertebrate renal tubules. Comparative Biochemistry and Physiology, 136: 479-498.

Oliaii, A. and B. Mobini, 2017. The histological differences of the ureter in Japanese quail (Coturnix japonica) compared with some other domestic avian species. International Journal of Morphology, 35(1): 193198. 08.06.

Pavek, T., 2007. Avian Euthanasia. Institutional Animal Cure and Use Committee, Cornell University. 7:

Reshag, A.F., D.A. Abood and S.D. Mohammed, 2016. Anatomical and histological study of the kidneys and salt glands in great flamingos (Phoenicopterusroseus). The Iraqi Journal of Veterinary Medicine, 40(1): 140-146.

Richardson, K.C., R.D. Woollier and G. Casotti, 1991. The relative size and asymmetry of kidneys in passerine birds from Australia and North America. Journal of Anatomy, 175: 181-185.

Sivakumar, S.A., S. Ushakumary and H.B. Sabiha, 2012. Micro-anatomical Studies On the Renal cortex of Guinea Fowl. Journal of Veterinaryand Animal Science., 8(1): 29-35.

Sreeranjini, A.R., M.p. Iyyangar, S. Gopinath, D. Pramodkumar and V. Haragopal, 2000. Histological and histochemical studies in kidney of Japanese quail. International. Journal of Veterinary Anatomy, 12(2): 169173.

Sreeranjini, A.R., M.P. Iyyangar and D. Pramodkumar, 2010. Histological Study on the Fibrous Architecture of Kidney and Ureter of Japanese Quail (Coturnix coturnix japonica). Tamilnadu, Journal of Veterinary and Animal Science., 6(2): 107-110.

Yaushira, T., T. Seiichiro, N. Takashi, T. Ryouta, A. Kazuhide, H. Satoshi, F. Masaru, K.S. Dwi and K. Takao, 2005. Expression of calbindin-D 28k in sporadic nephroblastomas of the chicken. Avian Disease., 50(1): 127-130.

Wright, P.A., C.M. Wood and J.M. Wilson, 2014. Rh versus pH: the role of Rhesus glycoproteins in renal ammonia excretion during metabolic acidosis in a freshwater teleost fish. The Journal of Experimental Biology, 217: $2855-2865$. 